\title{
Article
}

\section{The foci of in-action professional judgement and decision-making in high- level adventure sports coaching practice}

Collins, L., and Collins, D.

Available at http://clok.uclan.ac.uk/15367/

Collins, L., ORCID: 0000-0002-7478-1140 and Collins, D. ORCID: 0000-00027601-0454 (2017) The foci of in-action professional judgement and decisionmaking in high-level adventure sports coaching practice. Journal of Adventure Education and Outdoor Learning, 17 (2). pp. 122-132. ISSN 1472-9679

It is advisable to refer to the publisher's version if you intend to cite from the work. http://dx.doi.org/10.1080/14729679.2016.1227717

For more information about UCLan's research in this area go to http://www.uclan.ac.uk/researchgroups/ and search for <name of research Group>.

For information about Research generally at UCLan please go to http://www.uclan.ac.uk/research/

All outputs in CLoK are protected by Intellectual Property Rights law, including Copyright law. Copyright, IPR and Moral Rights for the works on this site are retained by the individual authors and/or other copyright owners. Terms and conditions for use of this material are defined in the policies page.

\section{CLoK}

Central Lancashire online Knowledge www.clok.uclan.ac.uk

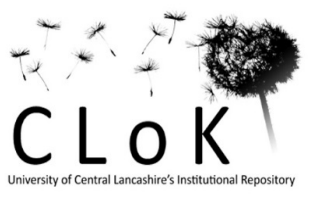


PJDM IN ADVENTURE SPORT COACHING

This is a pre-proof corrected manuscript, as accepted for publications, of an article published by Taylor \& Francis in the Journal of Adventure Education and Outdoor Learning on $26^{\text {th }}$ September 2016. Available online:

http://www.tandfonline.com/doi/abs/10.1080/14729679.2016.1227717?.journalCode=raol20

PLEASE REFER TO THE FINAL PUBLISHED VERSION FOR CITING PURPOSES

The Foci of In-Action Professional Judgement and Decision Making in High Level Adventure Sports Coaching Practice

Loel Collins*

And

Dave Collins

Institute of Coaching and Performance

University of Central Lancashire

Preston

PR1 2HE

*Correspondence concerning this article should be addressed to Loel Collins, Institute for

Coaching and Performance, University of Central Lancashire, Preston, UK, PR1 2HE. Email:

Email: lcollins2@uclan.ac.uk 


\begin{abstract}
This paper continues a theme of previous investigations by the authors and examined the focus of in-action reflection as a component of professional judgement and decision making (PJDM) processes in high level adventure sports coaching. We utilised a thematic analysis approach to investigate the decision-making practices of a sample of high level adventure sports coaches over a series of sessions. It was discovered that adventure sports coaches utilise a combination of questioning and observation to collect and constantly verify the information that forms the basis of their PJDM. Each coach responds to matters of immediate security, collecting information until a best fit decision can be made regarding changes to environment, task, or individual. Implications for professional training, accreditation, and development are presented against these data, offering a template for a more expertisefocused progression in the adventure sports coaching profession.
\end{abstract}

Keywords: Adventure, Coaching, Judgement, Decision Making, Epistemology 
The Focus of In-Action Reflective Practice as a Component of Professional Judgement and Decision Making in High Level Adventure Sports Coaching Practice

Professional judgement and decision making (PJDM; Collins \& Collins, 2012, 2013, 2014, 2015, 2016; Collins, Collins, \& Grecic, 2015) acts to synergise the complex interactive application of pedagogic and leadership skills associated with coaching practices in adventure sports coaching. Previous papers have highlighted the importance of PJDM in adventure sports coaching specifically as related to risk management (Collins \& Collins, 2013), the epistemological underpinning of the PJDM process (Collins et al, 2015), and the planning of programmes, linked sessions, and individual sessions (Collins \& Collins 2016). Notably, however, the focus of PJDM has not been investigated.

A rapid change in challenge level against sudden drops in clients' performance adds to the high PJDM load on adventure sports coaches. The highly dynamic and individualised nature of high-level adventure sports coaching places additional and significant emphasis on in-session thinking (Collins \& Collins, 2013, 2014, 2015). The constant auditing process proposed by Collins and Collins (2016), however, together with the maximisation of opportunities to conduct the audit (Collins \& Collins, 2014) still require the factors on which to focus the PJDM process to be understood.

Accordingly, the purpose of this particular paper was to investigate the significant factors addressed by the in-action PJDM within coaching practice. Adventure sports coaches require a reasoning framework for the PJDM process that is underpinned by a set of epistemological values. Accordingly, and to provide a theoretical context to this purpose, we first outline three closely linked papers by the authors that consider a) the epistemological and ontological underpinnings of the PJDM process in adventure sports coaching practice (Collins et al., 2015), b) the nature of PJDM in the planning and delivery of sessions (Collins 
\& Collins, 2016), and c) the integration of PJDM into the coaching act (Collins \& Collins, 2014).

a) Epistemological underpinnings: Collins et al. (2015) recognised the sophisticated epistemology that underpins high-level practice in adventure sports coaching. In particular, they proposed that the epistemological chain acts as a framework for a reflective/auditing process that characterises the dynamic coaching practice in adventure sports. The epistemological chain supports planning, pedagogy, professional development, analysis, and PJDM. The reflective act, by definition, is linked to the "reflector's" epistemological beliefs and ontological values.

b) PJDM in action: Collins and Collins $(2014,2015,2016)$ discovered that, in planning coaching activity, high-level adventure sports coaches drew on their epistemological values and domain specific expertise, then employed a synergy of classic and naturalistic decision-making processes to continually audit the evolving coaching process. A synergy of observation and questioning was utilised to collect information on which to base the PJDM process.

c) PJDM integration into the coaching process: Collins and Collins $(2014,2015)$ discovered that, in order to make judgments and decisions in practice, expert coaches employ a range of practical management strategies. These include pedagogic approaches, span of control, and time management approaches to facilitate decision-making regarding risk management, venue selection, aims, objectives, session content, and differentiation of the coaching process.

Thus, several questions emerge which help to structure the empirical examination of "in-action" PJDM in adventure sports. Specifically, what elements in the session does the adventure sports coach focus on in the PJDM process, what acts as critical knowledge for decision-making within the coaching process, and how is that knowledge prioritised and 
utilised?

\section{Method}

As stated, this paper outlines the findings from a larger study. A qualitative methodology was adopted to enable the breadth and richness of anticipated responses to be explored fully. In the present investigation, a thematic analysis of a purposive sample was employed to enable in-depth investigation of the themes that occur and reoccur in the PJDM of the coaches over a series of sessions. A thematic analysis approach was adopted to enable the researchers to explore, in depth, the multiple interpretation of the process by the participants. In this case, the "dynamic processes" of the planning process were explored by combining semi-structured interviews with video footage of the session (Lyle, 2003; Muir \& Beswick, 2007; Rosenstien, 2002). Video was used to stimulate the interview process and deepen the content and richness of the resultant data (cf. Cohen \& Manion, 1994). A broadly constructivist stance has been adopted.

\section{Participants}

Data sources included interviews with five British adventure sports coaches $\left(M_{\text {age }}=\right.$ $50.3, S D=9.1$ ); video and semi-structured interviews from 10 (two per participating coach) non-related sessions of adventure sports activity. Participants were recruited on the following basis: a) Holding multiple BCU Coach Level Five awards and/or National coaching roles; b) actively engaged in adventure sports coach activity; c) active as an adventure sports coach educator; d) willing to unpack and reflect on their own coaching practice; e) well regarded by their peers, and; f) availability. No incentive was offered and specific demographic information has been withheld to protect anonymity. Table 1 presents an outline of the qualification and experiences held by the participating coaches. Purposive sampling was used to ensure a seniority, experience, and inherent quality (at least of self-reflection) in the 
participants in order to generate a picture of high-level performance. Thus, the participating coaches had a combined 157 years of adventure sports coaching experience in whitewater kayaking, sea kayaking, surf kayaking, canoeing, mountaineering, rock climbing, mountain biking, and Alpine skiing. All enjoyed high status within the field, and were active as coach educators. In the absence of more effective or objective markers (cf.et al., 2012), we were confident that this sample presented a picture of good practice.

The primary investigator, a 50-year-old male, has 30 years of experience as an adventure sports coach within the National Centres in the UK. He is a coach educator for the British Canoe Union (BCU), holds the BCU's Level 5 Coach award in four disciplines, and is a qualified mountaineering and ski instructor. The researcher had a good rapport with the participating coaches.

\section{Procedure}

The investigation followed a staged process in which a pre-project, semi-structured interview was completed to gain data on the overall philosophy and epistemology of each participant coach using the approaches outlined in Collins et al. (2015) and Braun and Clarke(2006). For the present investigation, pre-session, semi-structured interviews, observation, and video of two non-related sessions, and post session interviews generated a video-text for each session. Interview guides were constructed and adjusted prior to use through piloting with three similarly qualified coaches. General questions (see Table 2) were used to scaffold the interview process; however, these were not always utilized or asked verbatim depending on the breadth and depth of answers provided at the time. This approach allowed emergent themes to be explored, revisited, and reconsidered. The empathetic, openly structured interviews varied in length $\left(M_{\text {duration }}=28.5 \mathrm{~min}\right.$ of topic-specific material $)$. Interviews were digitally recorded, transcribed using a commercial transcription service, analysed, and repeatedly re-analysed. Sessions were video recorded using discrete Hero2HD 
body/chest mounted cameras: one worn by the participating coach and the second by the primary researcher.

\section{Data Analysis}

The videotexts were read and re-read several times and reviewed in line with procedures suggested by Aronson (1994), Braun and Clarke (2006), and Fereday and MuirCochrane (2006). Firstly, videotexts where read and corrected while listening to the original digital recording in order to imagine the voice of the participants in later reads and assist in a more "complete analysis" (Smith, Flowers, \& Larkin, 2012, p. 82). During later readings, these videotexts were subsequently reconsidered in terms of common, recurring, significant, and underlying themes. As primary themes and subsequent initial themes (Miles \& Huberman, 1994) emerged, they were grouped and categorised as appropriate Braun and Clarke (2006). All coded data were then reviewed, relationships identified, and a thematic map generated (Crabtree \& Miller, 1999). The thematic map was subsequently reviewed following each review of the interviews to identify internal and externally coherent patterns of themes. From this thematic map, the themes were further defined and refined.

The thematic analysis method adopted in this study is a hybrid of thematic approaches and incorporates an inductive, data driven approach (Boyatzis, 1998) together with the use of themes (Crabtree \& Miller, 1999). The relationship of findings in this study and those outlined in Collins et al. (2015) is considered specifically throughout the discussion.

To enhance the study's trustworthiness (Morrow, 2005) and given the first author's experience in the field, bracketing was utilised. The researchers maintained a reflective and reflexive commentary throughout the process, bracketing personal experiences and considering the influence of personal values during the interviews and analysis (Smith, 2011). As an experienced adventure sports coach the primary researcher identified and recognised the impact of assumptions on the direction, rational and content of sessions that may be 
biased by a personal epistemological position. This resulted in the focusing of the semistructured interview in response to the participants' responses and greater exploration of the participants' reasoning within both interviews, an iterative process. The use of interview and video further acts to enhanced credibility of the study by triangulation (Morrow, 2005)

External and internal member checking was also utilised post-analysis to guard against misinterpretation, researcher subjectivity and increase credibility (Morrow, 2005). An independent investigator (a colleague within the same faculty who was unrelated to the study) was utilised as an external check. The participating coaches and co-author provided internal checks (Sparkes, 1998). In cases where this step identified a disagreement between members of the research team, each investigator reread the original transcript, discussed the coding, and a consensus was reached.

\section{Results and Discussion}

Initial analysis identified 35 codified units. The units were subsequently grouped into 4 themes. These were collated into 3 mid order themes and then combined into 2 higher order themes (see Table 3) and represented in a thematic map (see Figure 1). In line with Braun and Clarke (2006), we have provided examples of the themes from the data samples and have varied the length of quotes to demonstrate the depth and richness found in the data.

\section{Developing a Mental Model}

The continual auditing process utilised a synergy of observation and questioning to underpin the PJDM and link the planning to the in-action aspects of judgment and decision making regarding each individual being coached. To individualise and differentiate the coaching process, the adventure sports coach initially developed a mental model for each student. This model focused on the performance of the individual in context (technical and tactical) and a pedagogic behaviour (learning skills). This synergy of observation and 
questioning was applied both in and out of context by the adventure sports coach. These elements of the individualised mental model enabled the adventure sports coach to anticipate responses to the situations encountered, and provided a template that formed part of the auditing in regard to the technical and tactical performance and also the capacity of the individual as a learner (cf. Collins \& Collins, 2014). In particular, this collecting and auditing process enables the adventure sports coach to maintain a current/ live model of the individual. Coach 5 described this as "constantly analysing" and articulates this in a series of questions part of his decision-making and reflective process:

Where I'm going for the day... how long I'm going to use a [water/ location/ venue] feature...Have I matched...have I pitched it right? Are they too aroused, and therefore they can't cope with the learning...or are they a bit too...has it been too tame, and therefore not motivated enough to go on with it?

Clearly, Coach 5 addressed the selection of venue and its intensity relative to the students as a constant but simple process. Coach 1 described and reflected on the reason for a change in his approach to a particular student, based on an adjustment to the pedagogic mental model:

David who, as the week progressed, has kind of changed into, rather than being being totally disinterested, he's kind of needs to sit and watch a lot before...before it... watch peers rather than...I think he takes a majority of his stuff in visually, and thinks a bit about it...I would say say probably 70 watching, 30 thinking.

Coach 1 also alluded to the learning style of the student (cf. Fleming, 2002; Honey \& Mumford, 1982) which, whilst a questionable construct, is clearly part of his strategy to think through and plan the individualization of their session. This demonstrates a willingness by these coaches to utilise pragmatic and best fit concepts in an adapted and personalised 
manner. The individualized use of the learning model sustains the individualised coaching process. However, there remains a safety imperative.

\section{A Safety Imperative?}

Given the nature of the dynamic environments encountered by the adventure sports coach, it is not surprising that the initial focus of the PJDM process is safety (i.e., is the session safe to continue?). If the answer is yes, the activity proceeds, which enables further collecting of information regarding the student and, in turn, contributes to the mental model. If the answer is no, subsequent questions follow: Can the adventure sports coach alter the session to make it safe? If so, should that be a change of task (i.e., reset the goals), environment (i.e., change the location) or the individual (i.e., change in technique or tactic)? Interestingly, the activity is not made completely safe; rather, it is made 'acceptably' safe dependant on the developmental benefit of the proposed activity using a risk benefit analysis as outlined by Collins and Collins (2013).

Outwardly, the process of information collection, varying the interaction of the environment, task or, individual, and the audit of that process is a simple cycle. The expertise is manifest in the nuances of its application. This simple process is time framed by the development of the student and the willingness of the adventure sports coach to expose the student to the hazard repeatedly, thus increasing the risk. While the number of practices increases the exposure of the student to the hazard, the resultant skill development reduces the likelihood of harm.

Coach 4 highlighted the dilemma faced in balancing activity, group ability, and level of supervision:

The place I was most concerned about was them going around the bottom of the island because, though it was exceptionally unlikely that any of them would swim, IF [speaker's emphasis] they swam there, it would be a chase to catch 
them. So I've got my boat in a position where I can chase. Another day with another group. I would be out there sitting on the edge of one of those eddy lines ready to give, to sort. But I had a good team there and I felt they were unlikely to swim. I had to have my boat at hand but beyond that it's, you know, a judgment call based experience and an assessment of the people.

The desire to develop independent performances requires the coach to sit back and employ a watchful neglect approach in which the level of supervision is apparently decreased to encourage greater independence for the participants. This independence is viewed as a developmental benefit, reflecting the epistemological position of the coach (cf. Collins et al., 2013)

\section{An Integration of Observation and Questioning}

The synergy of observation and questioning checks and cross checks the adventure sports coach's assumptions about an individual at any particular moment and enables the adventure sports coach to generate a "working," best-fit hypothesis for development in which the anticipated rate of development is considered against the bigger picture of the environment and long-term aims. Coach 2's comments on meeting the group after allowing them unsupervised activity reflected this challenge:

I didn't know, by the time they arrived at their lunch spot how effectively they were moving their boats through the water. I needed to review that, so while I had a starting point for the session [day], I didn't know where I was going to and I was quite willing to simply try to work with six individuals rather than one group.

Coach 2 was considering the process within the short- and mid-term goals of the session, while clearly encouraging behaviours in line with the long-term goals (cf. Collins et al., 2015). Coach 2 was left with a challenge at this point, however: How many times could a 
performance be observed? The aforementioned implications of repeated exposure to risk are clear; coaches engaging in multiple observations may expose the student to greater risk (cf. Clark, Stamm, \& Urquia, 1979; Hay \& Ried, 1982; Morrison \& Reeve, 1992). Indeed, Knudson and Morrison (2002) acknowledge that repeated observations may well be impractical and dangerous.

To counter this risk, coaches engage in a type of 'verbal simulation'. Questioning acts to potentially reduce the number of observations required, and increases the richness of the information available to the adventure sports coach. Coach 3 described the questioning as providing "colour to the picture." Questioning is also utilised to encourage greater understanding of the technique, tactics, or process by the student. Encouraging students to consider other tactics or techniques, and relating them to particular affordances, deepens their understanding. Questioning can also facilitate the student's own reflective practice and develop their awareness of his or her own performance. Notably, the balance of questions and observations alters depending on the long-term goals, immediate environment, immediate task, and the individual's learning profile. In this respect, the questioning acts a link between the information gathering and the rest of the coaching process, while also managing the exposure to risk.

\section{A Recurrent Dilemma}

Throughout the process, the adventure sports coach is faced with a recurrent dilemma; namely, having to decide to act or to store the information gathered and prioritise once the immediate safety imperative has been met. The adventure sports coach focuses on particular features in the performance as indicators to initiate a coaching intervention.

A pedagogic caveat. The complexity of such risk-benefit decisions is highlighted under the heuristic that the change in environment, task, or individual will cause an initial decline in performance. The adventure sports coach attributes this to the potential cognitive 
overload of participants, the novelty of the new experiences, or the new sensations being experienced. Coach 3 talked of "desensitising" the environment following a change in location by allowing students to explore the new venue prior to any coaching intervention. Any change (environment, task, or individual) that does not generate a compromise in safety utilises a minimum of two episodes of observations before any pedagogic action is taken. This decision is further complicated by the need to anticipate the potential development of the student; the anticipated benefit is considered against the immediate risk. It appears that the use of questions in the information gathering acts to deepen the information available to the adventure sports coach on which to anticipate student development and base the decision. As a consequence, we could expect the PJDM to improve with time and reflection. Developing reflexive/meta-reflective processes during training programs appears logical, pending investigation of this heuristic.

\section{Changes in Performance}

Clearly the coach's function is to facilitate a long-term change in an individual's performance; consequently, responding to the change in performance is not surprising. The nature of that response is dependant upon the nature of the change compared to the anticipated development (which is based on the adventure sports coach mental model for development of that individual). Changes audited against the anticipated progress may cause alterations to the proposed route, direction, and rate of development. Rapid changes, drops, or plateaux in performance all have the potential to act as a focus to stimulate action by the adventure sports coach. In this regard, it is crucial to identify that the long-term change in performance may not be manifested in changes to the observable performance, but may become apparent in comprehension of the environment, technique, tactics, or affordances for action. 
Clearly, the stage of learning of the student and the desired performance skill being targetted (cf. Collins et al., 2015) require the adventure sports coach to address the cognitive aspects of performance in a manner akin to Vickers's (2007) decision training model. Consider this quote from Coach 5, 'The end point isn't just about moving the boat and the environment; it's also about controlling the psychology and that's one of the crucial components they [the student] have to develop."

\section{Changes in Student Behaviour}

Many of the Adventure Sports Coaches in this study reported responding to the behaviour of the students as indicators for action. Eye contacts, body language, disengagement in activities, the nature of responses, and changes in learning behaviour were all cited as components in "reading the student." Many of these factors may be described as interaction with the learning process. Coach 5 highlighted a change in behaviour that was explained by the student as an "old injury." The injury had not been problematic during previous sessions, but became an issue when the intensity of the environment was increased and was used by the student to avoid activity at that location. Coach 5 brought together the change in environment and behaviour as an indicator to act. Coach 1 responded to a student who sat out of a complex task by asking the student, "Would you like me to show you what to do...would you like me to explain it differently for you? ... or do you want to give it a go and then come back to me?" Once again the change in task was linked to a behavioural change. He then presented the same task in a different manner that suited the individual at the time. The pragmatic use of Fleming's (2002) learning styles model the Visual, Auditory, Reading and Kinesthetic modes of learning, demonstrates its utility as a communication tool rather than learning style the end result being activity and reflection that facilitate learning. Many of these responsive behavioural changes are treated as indicators of fatigue, frustration, boredom, loss of confidence, loss of rapport or lack of understanding of the task 
set. Consequently, given the potential for misunderstanding, the response to changes in behaviour is frequently a question. This questioning establishes the extent of the student's engagement with the learning process and, therefore, the adventure sports coach's actions. In particular, this establishes if the student's behaviour aligns with the coach's evolving plan and the potential adaptations that may be required; it is a guided reactive process. This also reflects the extent to which adventure sports coaching is a cognitive process: What cognitive skills are required by the adventure sports coach and to what extent are they addressed in training?

\section{General Discussion}

The auditing highlighted by Collins and Collins $(2013,2016)$ is a comparatively simple process, whereby adventure sports coaches monitor the progress of a student against the coaches interventions. The complexity arises in the nuances associated with the application and adaptation of the process, rather than in its' replication (cf. Collins, Collins \& Carson, 2016). This raises a question of whether adventure sports coaching is or can ever be a simply procedural approach and it challenges the current employment of competency-focused training and assessment for coaches in favour of a combined process that includes a decisionand judgment-focused approach (c.f. Collins, Carson and Collins, in review). This attention to the nuances, adaptability, and flexibility may be best described as the expertise of the adventure sports coach. Adaptability, flexibility, and innovation are demonstrated by the integration and variation of constraints based on the individualised mental models developed by the adventure sports coach.

The mental model held by the adventure sports coach is driven by the interaction with the environment, not the task of using the tools in that environment. It is not the ability to use 
the paddle or boat; rather, the tools are considered extensions of the individual that enable interaction with the environment (cf. Davids, Button, \& Bennett, 2008). As such, this concept differs from classic views of constraints led coaching theory in which the tools are considered part of the task. This finding should be considered alongside our findings (Collins \& Collins, 2015) in which adventure sports coaches manipulate constraints as a cognitive aspect of the coaching process. Of course, the "personal integration" of the tools (paddle, boats0 is likely to alter in relation to the stage of learning of the individual. This would lead to a focus in the early developmental stages of learning on utilizing the tools and, in the later stages, incorporating the environment by using the tools.

\section{Conclusion}

A mental model of performance is the predominant focus of high level adventure sports coaches, as would be expected given the technical understanding required in sports coaching. Interestingly, however, the adventure sports coaches also develop mental models of the individuals they coach as learners through an extensive process of observation and questioning both in and out of context.

Building from this initial assessment and modelling process, a synergy of observation and questioning is utilised to gain as rich profile of the student. Information is gained with which the adventure sports coach can anticipate development and tailor responses while coaching. Through these methods, the adventure sports coach considers the safety of the learning environment and the physical safety of the individual in that context. Determining the security of the learning environment is a risk-benefit decision, as outlined in Collins and Collins (2013). Adventure sports coaches' primary focus is on using information to constantly balance risk against benefit. 


\section{References}

Aronson, J. (1994). A pragmatic view of thematic analysis. The Qualitative Report, 2(1), 1-3. Retrieved from http://www.nova.edu/ssss/QR/index.html

Britsh Canoe Union. (2010). Canoe England (BCU) Level 2 Assessment Candidate Guide, version 2 viewed http://www.canoe-england/media/pdf/ CELevel 2CandidateGuide to Completeting Assessment portfolio V1-2. Pdf viewed 30 August 2013

Boyatzis, R. E. (1998). Transforming qualitative information: Thematic analysis and code development. Thousand Oaks, CA: Sage.

Braun, V., \& Clarke, V. (2006). Using thematic analysis in psychology. Qualitative Research in Psychology, 3(2), 77-101. http://dx.doi.org/10.1191/1478088706qp063oa

Clark, J. E., Stamm, C. L., \& Urquia, M. F. (1979). Developmental variability: The issue of Reliability. In G. C. Robert \& K. M. Newell, Psychology of motor behaviour and sport (pp. 253-257). Champaign, IL: Human Kinetics.

Cohen, L., \& Manion, L. (1994). Research methods in education (4th ed.). London, UK: Routeledge.

Collins, L., \& Collins, D. (2012). Contextualising the adventure sport coach. Journal of Adventure Education and Outdoor Learning, 12(1), 81-93. doi:10.1080/14729679.2011.611283

Collins, L., \& Collins, D. (2013). Decision-making and risk management in adventure sports coaching. Quest, 65(1), 72-82. doi:10.1080/00336297.2012.727373

Collins, L., Collins, D., \& Grecic, D. (2015). The epistemological chain in high level adventure sports coaches. Journal of Adventure Education and Outdoor Learning. doi:10.1080/14729679.2014.950592

Collins, L., \& Collins, D. (2014). Integration of In-Action Reflective Practice as a Component of Professional Judgment and Decision Making in High Level 
Adventure Sports Coaching Practice. Journal of Sports Science. doi.org/10.1080/02640414.2014.953980

Collins, L., \& Collins, D. (2015). Professional Judgment and Decision Making in Sports Coaching: The Role of Interaction. Journal of Sports Science. doi: 10.1080/02640414.2015.1105379.

Collins, L., \& Collins, D. (2016). Professional Judgment and Decision Making in the Planning Process of High Level Adventure Sports Coaching Practice. Journal of Adventure Education and Outdoor Learning. doi.org/10.1080/14729679.2016.1162182

Collins, D, J., Collins' L. \& Carson, H, J. (2016). "If it feels right, do it": Intuitive decision making in a sample of high-level sport coaches. Frontiers

Crabtree, B. F., \& Miller, W. L. (1999). Using codes and code manuals: A template organizing style of interpretation. In B. F. Crabtree \& W. L. Miller (Eds.), Doing qualitative research (2nd ed., pp. 163-177). Newbury Park, CA: Sage.

Davids, K., Button, C., \& Bennett, S. (2008). Dynamics of skill acquisition: A constraints led approach. Champaign, IL: Human Kinetics.

Fereday, J., \& Muir-Cochrane, E. (2006). Demonstrating rigor using thematic analysis: A hybrid approach of inductive and deductive coding and theme development. International Journal of Qualitative Methods, 5(1), 80-92. Retrieved from http://www.ualberta.ca/ iiqm/backissues/5_1/html/fereday.htm

Fleming, N. (2002). A guide to learning styles. Retrieved from http://www.vark-learn.com Hay, J. G., \& Reid, J. G. (1982). The anatomical and mechanical bases of human motion. Englewood Cliffs, NJ: Prentice Hall.

Honey, P. \& Mumford, A. (1982). Manual of Learning Styles. London: P Honey 
Knudson, D. V., \& Morrison, C. S. (2002). Qualitative analysis of human movement (2nd edition). Champaign, IL: Human Kinetics.

Lyle, J. (2003). Stimulated recall: A report on its use in naturalistic research. British Educational Research Journal, 29, 861-878. doi:10.1080/0141192032000137349

Miles, M. B., \& Huberman, A. M. (1994). Qualitative data analysis (2nd ed.). London, UK: Sage.

Morrison, C. S., \& Reeves, J. (1992). Perceptual style and instruction in the acquisition of qualitative analysis of movement by majors in elementary education. Perceptual and Motor Skills, 74, 579-583. doi:10.2466/pms.1992.74.2.579

Morrow, S, L. (2005). Quality and Trustworthiness in Qualitative Research in Counselling Psychology. Journal of Counselling Psychology

Muir, T., \& Beswick, K. (2007). Stimulating Reflection on practice: Using the supportive classroom reflection process. Mathematics Teacher Education and Development, 8, 74-93. Retrieved from http://www.merga.net.au/node/42

Nash, C., Martindale, R., Collins, D., \& Martindale, A. (2012). Parameterising expertise in coaching: Past, present and future. Journal of Sports Sciences, 10, 985-994. doi:10.1080/02640414.2012.682079

Rosenstein, B. (2002). Video use in social science research and program evaluation. International Journal of Qualitative Methods, 1(3). Retrieved from http://www.ualberta.ca/ ijqm

Smith, J. A. (2011). Qualitative psychology: A practical guide to research methods (2nd edition). London, UK: Sage.

Smith, J. A., Flowers, P., \& Larkin, M. (2012). Interpretative phenomenological analysis: Theory, method and research. London, UK: Sage. 
Sparkes, A. C. (1998). Validity in qualitative inquiry and the problem of criteria: Implications for sport psychology. The Sport Psychologist, 12, 363-386. Retrieved from http://journals.humankinetics.com/

Vickers, J. N. (2007). Perception, cognition, decision training: The quiet eye in action.

Champaign, IL: Human Kinetic. 